\title{
Plásticos e meio ambiente: analisando fenômenos ambientais complexos em visualizações de dados
}

\author{
Plastics and the environment: analyzing complex environmental phenomena \\ in data visualization
}

Rodolfo Augusto de Araujo Almeida, Doris Kosminsky

antropoceno, hiperobjetos, visualização de dados, complexidade

O presente artigo analisa diferentes estratégias de representação de fenômenos ambientais complexos empregando visualização de dados, tendo como base o conceito de hiperobjeto postulado por Timothy Morton (2013). O termo hiperobjeto descreve um objeto de escalas espaciais e temporais muito além do alcance da cognição humana, de tal forma que a compreensão humana a seu respeito é dificultada. No contexto do Antropoceno (um novo período da história geológica marcado pela ação do humano sobre o planeta), o desenvolvimento de uma consciência ecológica coloca-se como fundamental para a imaginação de futuros menos catastróficos. Neste contexto, o imaginário visual coletivo apresenta-se como uma peça-chave. Este artigo busca compreender as dificuldades encontradas pela visualização de dados na representação desse tipo de fenômeno, destacando suas potencialidades. Empregando questões formuladas a partir do conceito de hiperobjeto, analisamos três visualizações de dados ambientais relativas ao descarte de plásticos. Com este texto, pretendemos contribuir para a reflexão sobre os efeitos da ação humana sobre o planeta, fornecendo uma estrutura de análise de visualizações que pode vir a ser empregada em projetos futuros que abordem temas relacionados.

anthropocene, hyperobjects, data visualization, complexity

The present article analyzes different strategies for representing complex environmental phenomena employing data visualization, based on the concept of hyperobject posited by Timothy Morton (2013). The term describes an object of spatial and temporal scales far beyond human cognition, so much so that human understanding about it is made difficult. In the context of the Anthropocene (a new period of Earth's geological history defined by anthropic impacts over the planet), the development of an ecological consciousness is fundamental to redirect efforts towards the imagination of less catastrophic futures. In this context, the collective visual imaginary is also a key element. This article strives to understand the difficulties found by data visualization when representing these types of problems, underlining its potential for such. Based on the concept of hyperobject, we formulate questions and use them to analyze three visualizations of environmental data related to plastics. This article intends to contribute to the reflection about the effects of human activity over the planet by providing a framework for visualization analysis which may be applied in future projects on related subjects.

Anais do $10^{\circ} \mathrm{CIDI}$ e $10^{\circ} \mathrm{CONGIC}$

Kelli C.A.S. Smythe, Rafael de Castro Andrade (orgs.)

Sociedade Brasileira de Design da Informação - SBDI

Curitiba | Brasil | 2021
Proceedings of the $10^{\text {th }} \mathrm{CIDI}$ and $10^{\text {th }}$ CONGIC

Kelli C.A.S. Smythe, Rafael de Castro Andrade (orgs.)

Sociedade Brasileira de Design da Informação - SBDI Curitiba | Brazil | 2021 


\section{Introdução}

A situação climática em que o planeta se encontra desde pelo menos a metade do século $X X$ (Steffen et al, 2015) desafia a capacidade humana de compreender, nomear e visualizar os fenômenos com que nos deparamos. De "aquecimento global" a "mudança climática" e, mais recentemente, "crise climática" parece haver na capacidade de nomear uma importante faculdade de compreensão, aproximando o público de um problema que parece distante (Jaskulsky \& Besel, 2013).

A mudança causada pela ação humana sobre o planeta é profunda a tal ponto que está no cerne de um conceito das geociências que vem sendo também objeto de estudo das humanidades: o Antropoceno. O termo foi cunhado na década de 1980 por Eugene $\mathrm{F}$. Stoermer e mais tarde delineado e popularizado por Paul Crutzen (2000), e propõe uma revisão das classificações do tempo geológico da Terra. De acordo com essa proposta, não estaríamos mais vivendo no Holoceno (iniciado há aproximadamente 12 mil anos), mas adentrando um novo período marcado pelo impacto humano sobre a Terra. A ideia já era considerada desde pelo menos o século 18, sob nomes como "a época humana", o período "antropozoico", e a época "recente" (Maslin \& Lewis, 2015): tentativas de descrever o período que compreende a existência da espécie humana. Na proposta de Crutzen, porém, é o impacto e não apenas a existência do ser humano a principal marca do período. A adoção dessa classificação segue em debate nas geociências - com críticas contundentes, por exemplo, por parte de pensadores indígenas que citam não o ser humano genericamente como agente dessa mudança, mas os modos de vida e de desenvolvimento econômico que apartam o homem da natureza (Krenak, 2019).

Ainda há ausência de consenso entre pesquisadores sobre quais os marcadores estratigráficos (os eventos que marcam o início do período) do Antropoceno. Um dos mais considerados é o processo chamado de A Grande Aceleração: um termo guarda-chuva que abarca a evolução exponencial de toda sorte de indicadores - como emissões de carbono e microplásticos, temperatura média global e acidificação dos oceanos - que se deu a partir da metade do século XX. Maslin e Lewis (2015) apontam ainda como possíveis marcadores os anos de 1610 (por conta da movimentação de espécies ao redor do globo como consequência das Grandes Navegações) e 1964 (quando culminam processos de industrialização da Grande Aceleração).

A crescente velocidade dos modos de vida na Terra se reflete também em nosso ambiente informacional: a quantidade descomunal de dados coletados, armazenados e analisados culminou no advento, na década de 1990, do termo Big Data. Ele descreve bases grandes demais para transformar e manipular com o ferramental usual até ali, demandando novas soluções tecnológicas e formas de tirar insights e refletir sobre esses dados.

O design vem tratando de questões ambientais desde a década de 1970, quando Victor Papanek (1971), preocupou-se em colocar o meio ambiente em diálogo com as práticas de designers. O filósofo Bruno Latour (2008) identifica também no design a possibilidade da formação de caminhos mais equilibrados ecologicamente. A visualização de dados, dentro do 
campo do design de informação, trata historicamente de representar modelos que explicam fenômenos do mundo traduzidos na forma de dados (Cairo, 2013). Nesse contexto, ela também têm se tornado crescentemente complexa e imersiva em diversas de suas manifestações levando à proposição de denominações como "hiperinfografia" (Longhi \& Cordeiro, 2018). Este artigo busca compreender as dificuldades encontradas pela visualização de dados na representação de fenômenos climáticos, destacando suas potencialidades. Para tanto, serão analisados três projetos que abordam a problemática do descarte de plásticos no contexto da crise climática, tendo como base o conceito de hiperobjeto desenvolvido por Timothy Morton.

\section{Hiperobjetos}

Para compreender como fenômenos ambientais de grande complexidade são representados na visualização de dados, convém antes conceituar o que entendemos como complexidade, suas características e quais fenômenos se enquadram nessa classe. Nos baseamos, para isso, na visão de Morton, que entende a complexidade como o que chama de malha: "uma série de eventos ou situações em que algo está enredado; uma concatenação de forças ou circunstâncias constritivas ou restritivas; um laço" (2010). A ideia dialoga com o paradigma da complexidade de Edgar Morin, que descreve não apenas um "tecido de acontecimentos, ações, interações, retroações, determinações, acasos, que constituem nosso mundo fenomênico", mas que compreende também "a incerteza no seio de sistemas ricamente organizados", proveniente seja dos fenômenos em si, seja dos "limites de nosso entendimento" (Morin, 1990). Como exemplo máximo da complexidade, Morton erige um conceito de que utilizaremos para a discussão dos projetos aqui analisados: o hiperobjeto.

Cunhado na esteira dos debates filosóficos do movimento chamado de ontologia orientada a objetos, o termo descreve de maneira genérica uma gama de objetos e ideias que se pode estudar, pensar sobre e aferir, mas que não são simples de se visualizar diretamente por conta de sua grande escala espacial e temporal $(2010,2013)$.

Morton (2015) cita o exemplo do isopor. Um único copo de isopor é perfeitamente perceptível e manipulável, mas o conjunto de todo o isopor disperso pelo mundo apresenta um desafio maior à imaginação. Dividido em partículas cada vez menores, o material espalha-se, ocupando uma escala espacial de nível global. Considerando os cerca de 500 anos necessários para sua decomposição, se estende também em uma escala temporal inimaginável, da ordem de séculos. É, dessa forma, um material produzido por humanos que desafia suas próprias capacidades de visualizá-lo como um todo, sobrevivendo à toda a população mundial viva hoje. A radiação de plutônio dispersa pelo planeta, a biosfera, e o aquecimento global são outros exemplos oferecidos pelo autor.

Segundo Morton (2013), cinco propriedades definem um hiperobjeto - e utilizaremos algumas delas para formar um conjunto de perguntas usado para analisar as visualizações de dados e compreender seu diálogo com o conceito: 
1. Viscosidade - hiperobjetos aderem a outros objetos independentemente da resistência que se oferece;

2. Não-localidade - hiperobjetos cobrem tamanha escala temporal e espacial que sua totalidade não pode ser percebida em nenhuma de suas manifestações locais;

3. Liquidez - hiperobjetos são tão maciços que distorcem a percepção de espaço e tempo como constantes, concretos e consistentes;

4. Multidimensionalidade - hiperobjetos ocupam um espaço dimensional superior, inacessível à percepção humana que os percebe tridimensionais apenas parcialmente;

5. Interobjetividade - hiperobjetos são formados por relações complexas entre diferentes objetos e se permitem perceber apenas pelas marcas que deixam entre si.

Se, por natureza, o conceito de hiperobjeto parece abstrato e ininteligível, ou pertencente apenas ao campo das ideias, o consideramos útil ao campo do design por não apenas nomear certo fenômeno, mas por nos permitir extrapolar as visualizações ambientais para uma classe de problemas, ao mesmo tempo que pode informar projetos de design em torno dessa problemática.

A visualização de dados possui seus próprios critérios para medir complexidade, sendo um dos mais comuns a listagem da quantidade de dimensões codificadas em um gráfico (llinsky \& Steele, 2011) - queremos aqui colocar esses critérios em contato com os de outros campos. A visualização é comumente usada para representar fenômenos complexos: ela pode representar dados de grandes quantidades ou multidimensionalidades; elucidar o funcionamento de sistemas intrincados e altamente relacionais; dimensionar fenômenos crescentemente grandiosos em escala; e como projeto de design, deve equilibrar uma série de preocupações com relação ao seu leitor final, de modo a estabelecer uma comunicação adequada ao seu perfil, contexto e suporte midiático (Cairo, 2013).

A publicação de coletâneas como Arts of Living on a Damaged Planet (Tsing et al., 2017) ou o catálogo Hyperobjects for Artists (Copelin et al., 2018) - associado a uma exposição de mesmo nome realizada em 2018 nos Estados Unidos - evidenciam que a questão já se colocou às artes. Nessas obras, poetas, ensaístas e artistas de outras disciplinas trazem suas potenciais respostas para endereçar esse problema de representação. A problemática do Antropoceno vem sendo, também, objeto de estudo dentro do design (Meyer, 2020). Gostaríamos aqui de nos concentrar sobre as respostas dadas especificamente pela visualização de dados como disciplina encarregada da representação da complexidade.

Os hiperobjetos representados, queremos argumentar aqui, podem ser vistos como fundamentalmente problemas de design na medida em que apresentam um desafio ao ferramental visual e comunicativo de que o ser humano atualmente dispõe para dar conta daquilo que é incapaz de visualizar cognitivamente. 


\section{Método}

Por natureza, os fenômenos representados nos projetos analisados aqui não possuem uma única resposta ou solução - ou sequer uma dezena delas. São problemas ecológicos, que dizem respeito a interações complexas entre milhares de atores ao redor da biosfera.

Compreendemos eles como problemas capciosos (wicked problems), como delineado por Rittel (1973): como tal, não procuramos aqui elencar qual seja a solução ideal para esses problemas de representação, mas, antes, tentamos entender como eles se enquadram dentro da estrutura conceitual dos hiperobjetos e se comportam como potenciais representações do conceito no campo do design.

Para isso, identificamos três dentre as propriedades dos hiperobjetos listadas anteriormente que - por suas características espaciais e temporais - podem ser identificadas nas visualizações de dados ambientais. A partir dessas propriedades, elaboramos questões que nortearão a análise e discussão dos projetos:

1. Não-localidade - a visualização representa o objeto de maneira diluída ou concentrada em determinado tempo e espaço?

2. Multidimensionalidade - a visualização representa o objeto somente naquilo que ele tem de perceptível a olho nu ou expõe outras camadas de percepção?

3. Interobjetividade - a visualização representa o objeto interagindo com outros e com seu entorno, ou isoladamente?

Articularemos essas perguntas com autores do campo do design da informação que podem nos ajudar a compreender os efeitos provocados pelas decisões de design empregadas nos projetos.

Nos concentraremos aqui em projetos que abordam um dos exemplos de hiperobjeto a que Morton mais costuma recorrer: o plástico. Como produto dos modos de consumo e organização econômica dos humanos, eles condensam simbolicamente vários dos marcadores do Antropoceno. A análise realizada aqui é fruto de uma revisão de projetos listados no portal e no repositório de inscritos na premiação Kantar Information Is Beautiful, instituição que reúne trabalhos de praticantes de renome, levando à seleção de três projetos que, cada qual à sua maneira, elucidam diferentes propriedades dos hiperobjetos com diferentes soluções de design. Nos deteremos na análise apenas de visualização de dados e das interações permitidas, descrevendo outros componentes gráficos apenas com fim informativo. Esperamos, assim, encontrar abordagens possíveis do problema e vias de diálogo entre o conceito do hiperobjeto e a visualização de dados. 


\section{Discussão de projetos}

\section{Drowning in Plastic}

A publicação jornalística digital Drowning in Plastic: Visualising the World's Addiction To Plastic Bottles $^{1}$ da agência de notícias Reuters pretende dimensionar a quantidade de garrafas plásticas vendidas diariamente ao redor do mundo partindo de dados da Euromonitor International. Uma animação inicial representa de maneira figurativa a quantidade de garrafas vendidas desde que o usuário acessou aquela página web na forma de uma "chuva" de garrafas plásticas renderizadas em 3D, tendo como comparação de escala uma figura humana e um caminhão - eventualmente soterrados pelo plástico.

Figura 1: Comparação visual entre a quantidade de garrafas vendidas em um dia e Torre Eiffel (captura de tela feita pelo autor na página web do projeto)

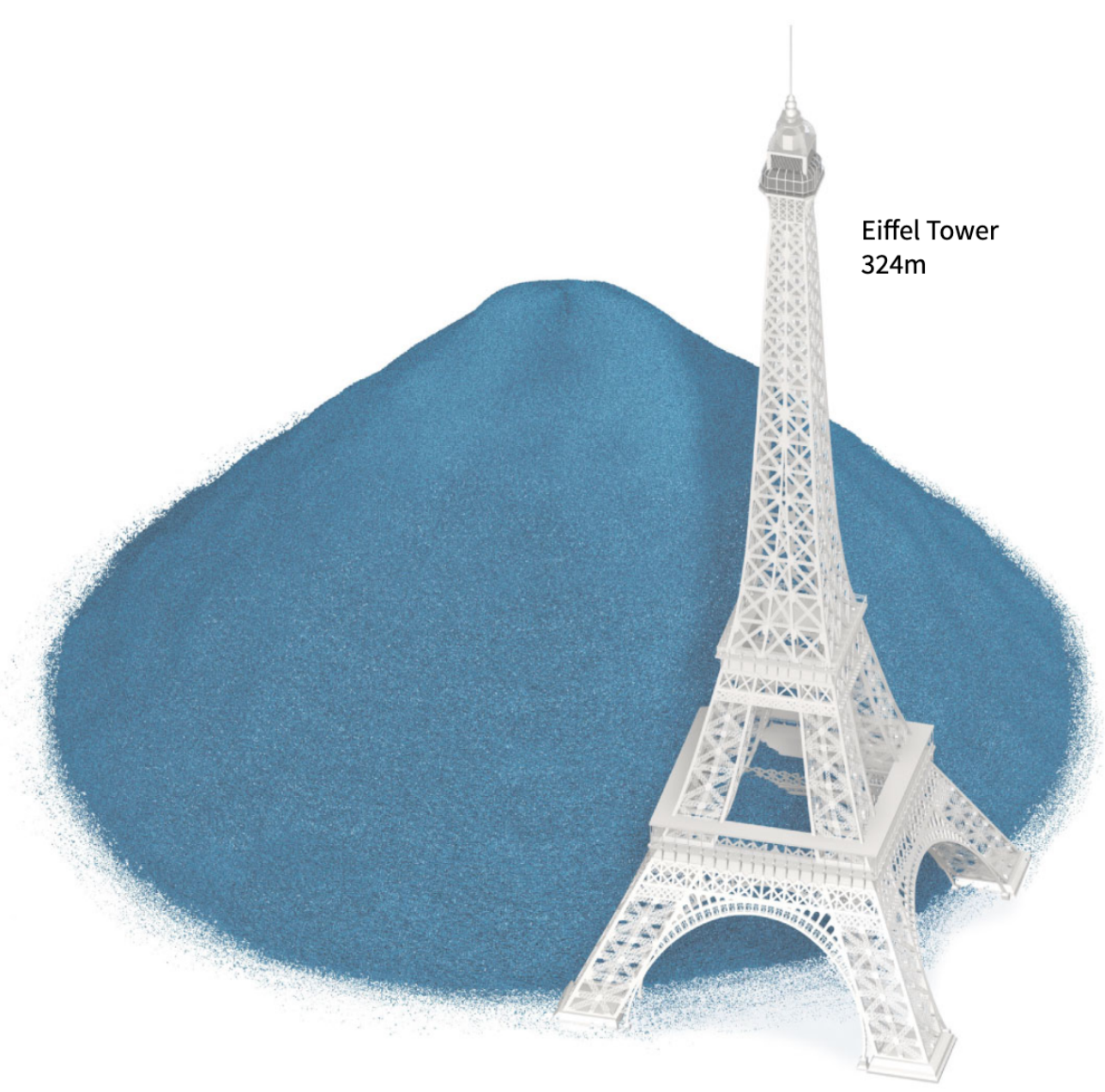

Usando de um expediente usual da infografia para dimensionar fenômenos, as comparações de escala são a principal estratégia de visualização: ao longo do material,

\footnotetext{
1 <https://graphics.reuters.com/ENVIRONMENT-PLASTIC/0100B275155/index.html>, acesso em abril de 2021.
} 
demonstra-se quantas garrafas são vendidas a cada hora, dia, mês, ano, e no acumulado da última década, formando montanhas azuis de garrafas que se acumulam, soterram e contrastam cromaticamente com marcos turísticos mundiais representados em tons de cinza, como o Cristo Redentor e a Torre Eiffel.

A linguagem discursiva sugere que o material se propõe menos a fornecer um panorama dos dados de forma neutra e desinvestida do que provocar um assombro e espanto ao leitor em leitura explanatória (Ilinsky \& Steele, 2011). Tal efeito comunicativo é acentuado pelo formato narrativo que apresenta os dados de forma particionada (promovendo o acúmulo de unidades de informação ao longo da leitura); usa estratégias de repetição (recorrendo à mesma visualização, cada vez com maior número de garrafas); e estabelece uma lógica vertical que reforça a ideia de crescimento descontrolado, características cabíveis em uma narrativa de dados, segundo descrito por Knaflic (2015). Um gráfico de sankey ${ }^{2}$ ao fim do material exibe qual o destino de todas essas garrafas, ressaltando visualmente por meio de um contraste de matiz a pequena proporção que efetivamente é reciclada.

Empregando o conceito de hiperobjeto na análise, entendemos que, em relação à propriedade de não-localidade, a visualização representa o objeto de maneira concentrada em tempo e espaço: as garrafas que atualmente estão dispersas pela biosfera, com impactos ambientais difusos, são literalmente reunidas pelo designer e percebidas como um todo unívoco, acumulado inerte em locais onde potencialmente permaneceriam por séculos. A visualização, assim, rompe a diluição espacial e temporal característica desse hiperobjeto. Em relação à propriedade de multidimensionalidade, a visualização representa o objeto apenas em sua constituição visível a olho nu, sem alusão às suas formas imperceptíveis (como microplásticos, por exemplo). Em relação à propriedade de interobjetividade, a visualização representa o objeto de maneira estática em relação a seu entorno: imóveis, essas pilhas de garrafas não demonstram interação com o restante dos objetos além de soterrá-los, prenunciando metaforicamente uma catástrofe de uma avalanche de plástico. A publicação menciona o impacto desse material sobre outras formas de vida, como a fauna marinha, apenas no texto escrito, sem representá-lo visualmente.

A imaginação de um cenário em que todas as garrafas de plástico vendidas mundialmente são acumuladas em uma única pilha é uma abordagem de representação dos hiperobjetos que objetiva trazê-los à escala humana e equipamento perceptivo humanos: na paisagem monocromática e minimalista dessas renderizações $3 \mathrm{D}$, o plástico aparenta ameaçar quase que exclusivamente o ser humano, ocupando o espaço de nossas metrópoles e disputando atenção com marcos turísticos históricos - símbolos da permanência da cultura e construção agora ofuscados pela ubiquidade de nossos objetos descartáveis.

${ }^{2}$ Utilizamos aqui as classificações de gráficos e codificações de Kirk (2019). 


\section{What Happens to the Plastic We Throw Out}

A publicação jornalística digital What Happens to the Plastic We Throw Out ${ }^{3}$ da revista National Geographic oferece um panorama do destino do plástico que chega aos oceanos do sudeste asiático, fazendo um estudo de caso da situação de um dos locais mais remotos do mundo, a ilha Henderson. Localizada no oceano Pacífico, no meio do caminho entre Nova Zelândia e Chile, a ilha desabitada detém a maior concentração de lixo plástico do mundo: mais de 18 toneladas de resíduos acumulados em 37 quilômetros quadrados de área terrestre. A partir de dados da organização The Ocean Cleanup, a publicação mostra como o lixo descartado em países da região (tanto em terra quanto no mar) chega até a costa da ilha via correntes marítimas, depositando-se sobre as praias e afetando a vida marinha ao redor.

Figura 2: Visualização do resíduo plástico proveniente de rios (captura de tela feita pelo autor na página web do projeto)

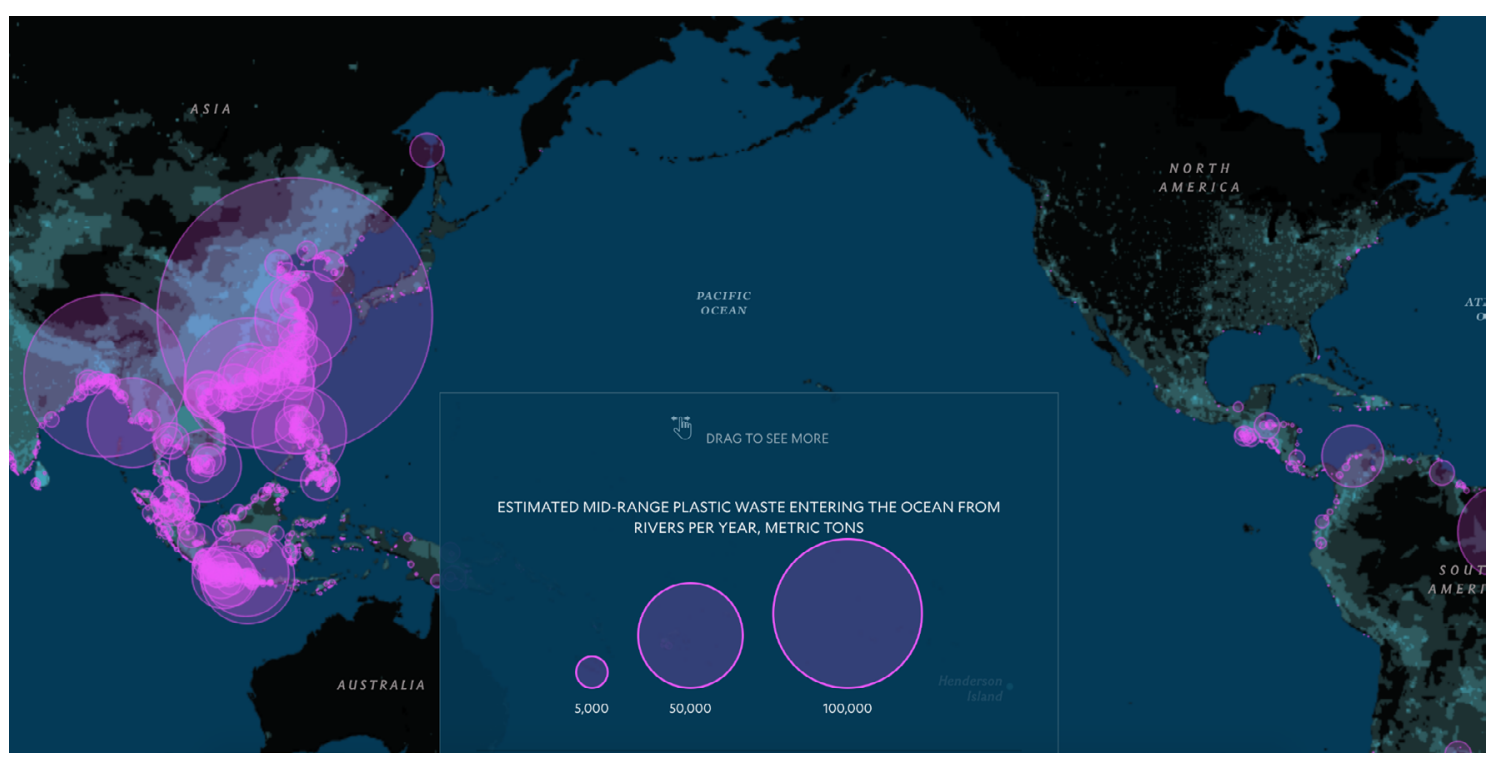

Em uma narrativa multimídia que combina vídeos e visualizações interativas e estáticas em um formato de scrollytelling, o projeto recorre a visualizações espaciais, fazendo uso de mapas coropléticos, mapas de densidade de pontos e gráficos de símbolos proporcionais. Os mapas permitem a interação apenas pela rolagem horizontal, clicando e arrastando o mouse para observar o mapa em áreas que escapam ao enquadramento latitudinal. Partindo da localização da ilha Henderson no Pacífico (acompanhada de imagens de vídeo de sua costa coberta por plástico), a narrativa nos leva ao sudeste asiático, demonstrando em um mapa coroplético a quantidade de plástico descartado incorretamente. A rolagem em seguida revela um mapa de densidade de pontos que traz a quantidade estimada de plásticos que adentram os oceanos anualmente por rios. Os círculos são então reaproveitados para a visualização seguinte: um gráfico de símbolos proporcionais, fora do ambiente do mapa, trazendo os 3 mil rios que mais

\footnotetext{
3 <https://www.nationalgeographic.com/magazine/graphics/the-journey-of-plastic-around-the-globe>, acesso em abril de 2021.
} 
servem de canal de entrada de plásticos no oceano. O texto complementar destaca que os 20 rios mais poluídos do mundo representam dois terços de todo o plástico que chega ao mar pelos oceanos. A narrativa elabora sobre esse ponto, voltando ao mapa isoplético e aproximando-o do rio Yangtze, na China, o mais poluído do mundo. Por fim, um mapa animado gerado a partir de um modelo de densidade de resíduos no oceano é exibido em conjunto com diagramas de setas representando correntes marinhas e visualizando como o material descartado chega, enfim, à ilha Henderson.

Empregando o conceito de hiperobjeto na análise, entendemos que em relação à propriedade de não-localidade, a visualização representa o objeto de maneira concentrada em tempo e espaço: a exibição parcial dos dados na visualização - não revelando toda a superfície do globo, e com especial atenção na narrativa ao sudeste asiático - sugere, mas não visualiza, a não-localidade característica dos hiperobjetos, concentrando o fenômeno em determinados pontos do globo. O mesmo vale para a temporalidade: a longa permanência desses materiais é sugerida na narrativa por meio de vídeos, mas as visualizações dão conta de um período apenas de até 72 meses (no caso da animação) ou até de um ano (no caso do restante dos gráficos), não sugerindo uma escala temporal que ultrapassa a dos seres humanos. Em relação à propriedade de multidimensionalidade, a visualização representa o objeto em sua constituição visível e invisível a olho nu (multidimensionalidade): o papel da ilha Henderson como metonímia de todo o plástico descartado no mundo fornece um retrato do descarte descontrolado de plástico, ao mesmo tempo em que localiza a narrativa ao redor desse ponto do globo. O título "o que acontece com o plástico que descartamos", ainda parece sugerir que todo o material chega, por fim, à essa ilha, não abordando os múltiplos destinos e dimensões que esse material ocupa. Ainda que não faça uso de representações figurativas, as visualizações se apoiam em representações abstratas para servir como objeto comum. A perspectiva que nos é dada, visualizando quantitativamente objetos descartados em certo local, se aproxima daquela que seríamos capazes de observar a olho nu, apenas agregada ao longo do tempo, sugerindo também uma dimensão superior a esses objetos que não podemos perceber imediatamente. Em relação à propriedade de interobjetividade, a visualização representa o objeto de maneira interativa em relação a seu entorno: a animação que encerra o material e os gráficos de densidade de pontos sugerem relações do plástico com correntes marinhas, hidrografias locais e grandes centros urbanos.

\section{Plastic Air}

Plastic Air é uma plataforma digital interativa de autoria de Giorgia Lupi, Talia Cotton e Phil Cox. O projeto propõe uma forma lúdica e exploratória de visualizar concentrações de microplásticos (partículas de diâmetro geralmente inferior a 5 milímetros) no ar a partir de dados de nove estudos que analisam o comportamento desses materiais.

${ }^{4}<$ https://artsexperiments. withgoogle.com/plasticair>, acesso em abril de 2021. 
Ao acessar a página, o leitor encontra um botão toggle que ativa ou desativa uma lente rotulada como "ver" ou "não ver". No estado "não ver", imagens de objetos feitos de plástico flutuam na tela e desaparecem diante de um céu representado por um gradiente azul claro. O clique do mouse por parte do leitor materializa novos objetos, rotulados textualmente por um tooltip como, por exemplo: "cabide feito de polietileno de alta densidade", "saco de salgadinhos feito de polipropileno orientado", ou "qualquer tipo de roupa feita de nylon e poliéster". Clicando repetidamente, o leitor despeja sobre o ambiente dezenas de objetos que prontamente desaparecem de vista. Já no estado "ver", o ponteiro do mouse acompanha um rótulo textual que descreve diferentes ações que o usuário pode simular: "pedir uma entrega de delivery", "ir às compras", "se maquiar", etc. Com o clique, os mesmos objetos anteriores são materializados, mas ao desaparecerem deixam consigo um rastro de partículas de microplásticos representadas por dezenas de pequenos símbolos coloridos (como linhas, triângulos, círculos e bastões, representando fibras, filmes, grãos e fragmentos de materiais respectivamente), que flutuam à esmo até deixar o enquadramento. Correr o ponteiro sobre esses símbolos traz mais informações como o tamanho da partícula, sua composição e possível origem. Um menu lateral traz legendas explicando as codificações das formas (que se dão em pelo menos três dimensões: símbolo, diâmetro, e quantidade de partículas) e permite mudar as condições de existência e comportamento das partículas (como por exemplo, mudar o ambiente de rural para urbano, ou as condições do céu para chuvoso ou com neve). Com a tela literalmente "poluída" pela grande quantidade de partículas, o leitor passa a encontrar maior dificuldade de selecionar uma partícula em específico - sobrepostas, elas se atrapalham e atropelam de forma caótica. Um botão no menu lateral rotulado "limpar" promete resolver o problema. Diante do clique do leitor, porém, nada muda na densidade de partículas e uma caixa de texto questiona: "você realmente achou que isso iria funcionar? Plásticos são feitos para serem duráveis. Uma vez que estão ali, não desaparecem".

Figura 3: Legenda e botões seletores à esquerda e visualizações animadas de partículas de plástico ao centro (captura de tela feita pelo autor na página web do projeto)

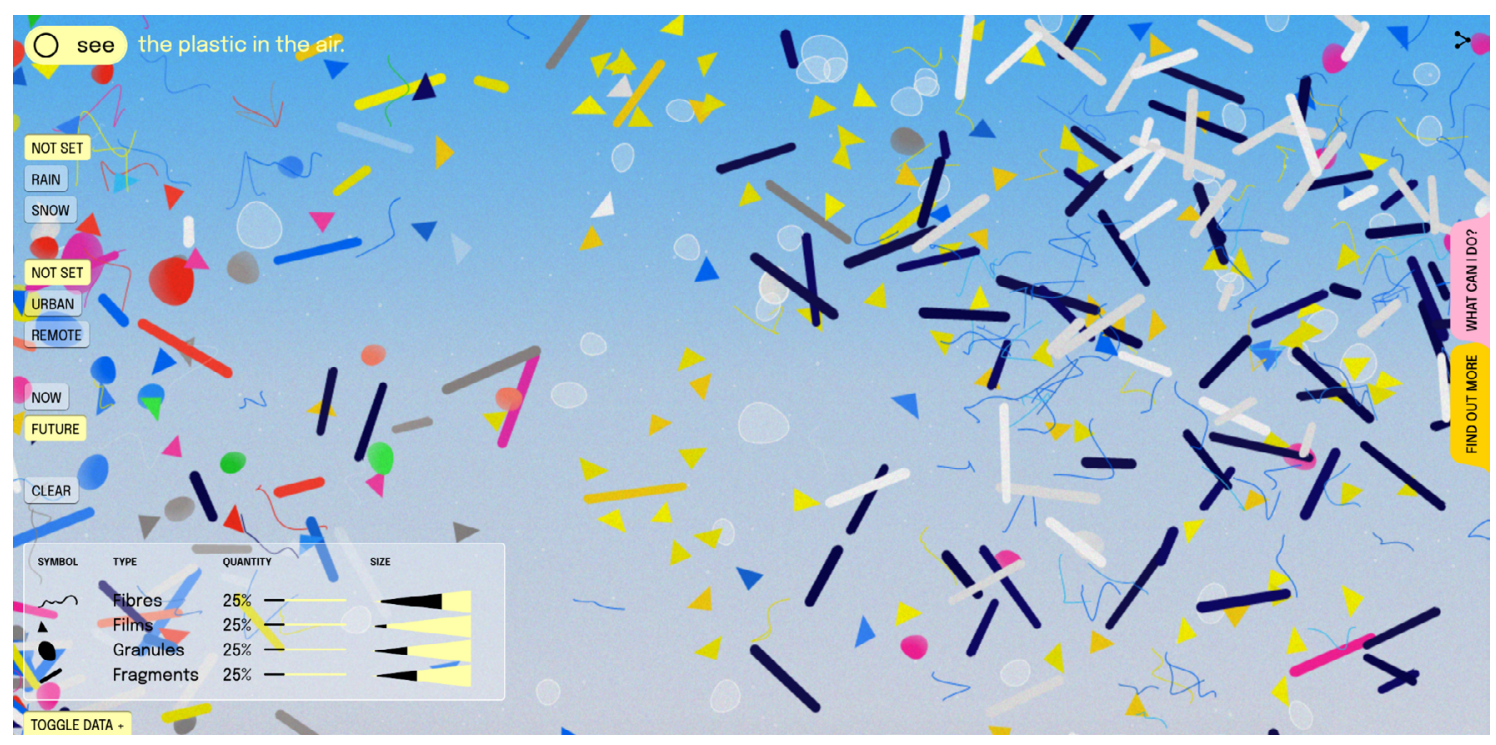


Empregando o conceito de hiperobjeto na análise, entendemos que, em relação à propriedade de não-localidade, a visualização representa o objeto de maneira diluída em tempo e espaço: a movimentação animada e caótica das partículas, sumindo do enquadramento, endereça o aspecto espacial diretamente, sugerindo uma localidade difusa, com objetos figurativamente diluídos no espaço e no próprio ar que respiramos. Em conjunto com o efeito de impotência provocado ao leitor pela promessa não-cumprida de limpar a interface de plásticos, o projeto reforça de maneira enfática o caráter quase permanente desses objetos e, portanto, sua diluição também no aspecto temporal. Em relação à propriedade de multidimensionalidade, a visualização representa o objeto em suas constituições visiveis e invisiveis a olho nu: a abordagem de representação do hiperobjeto aqui - valendo-se de uma das faculdades mais básicas do indivíduo, a de olhar - atua como uma "lente" ou "visão aumentada" da realidade. Partindo da realidade material, dos objetos como são percebidos a olho nu, o projeto então revela as suas formas imperceptíveis desse objetos que se sobrepõem àquelas que podemos ver. Em relação à propriedade de interobjetividade, a visualização representa o objeto em suas interações com o entorno. A conexão direta promovida pela visualização entre os comportamentos de consumo (ou ações do usuário) e a emissão de microplásticos no ar sugere uma forte interação do objeto com outros. Não apenas o objeto toma o cenário da visualização (ocupando todo o ar com microplásticos), mas ele o faz justamente por conta de sua interação com um humano, representado aqui pelo próprio leitor. Propicia-se, assim, um sentido de responsabilidade e agência: um simples clique do mouse (ou um simples ato de consumo individual) pode despejar sobre o ar partículas imperceptíveis porém duradouras.

É evidente que a ferramenta realiza uma simplificação da realidade natural à visualização de dados, na medida em que ações como "pedir delivery" envolvem potencialmente a emissão de ainda mais microplásticos em sua cadeia produtiva do que os representados pelos talheres descartáveis, por exemplo, e os padrões de comportamentos desses microplásticos na tela são limitados. Sem recorrer a codificações abstratas já bem estabelecidas na visualização de dados, como gráficos de barras, linhas ou histogramas (Kirk, 2019), a plataforma não parece pretender ser um dashboard de tomada de decisão. Não emprega-se a forma mais direta de se extrair uma informação numérica em linguagem neutra, como preconiza Edward Tufte (1983), prezando pela objetividade e funcionalidade como norte. Mas, antes, ela parece assumir que não basta apenas comunicar de forma neutra. $O$ trabalho busca oferecer uma lente para mirar a realidade, questionando a percepção e hábitos cotidianos por meio da instrumentalização da linguagem visual para alcançar um efeito emocional ou perceptivo de espanto. Dialoga, assim, com a visão de autores como D'Ignazio \& Klein (2020) que admitem, de antemão, a neutralidade como uma impossibilidade e sua própria defesa como uma ideologia. O lado direito da plataforma traz, ainda menus que ressaltam esse caráter "ativista" do gráfico: um traz documentação descrevendo fontes dos dados da plataforma; o outro, intitulado "o que eu posso fazer" orienta um suposto leitor tomado de consciência ecológica a interromper ou reduzir o uso de plásticos. 


\section{Enquadramento dos projetos}

A análise dos projetos à luz das três propriedades de hiperobjetos elencadas aqui (nãolocalidade, multidimensionalidade e interobjetividade) pode ser resumida na tabela 1.

Tabela 1: Enquadramento dos projetos nas propriedades

\begin{tabular}{llll}
\hline Projeto & $\begin{array}{l}\text { Propriedade de } \\
\text { Não-localidade }\end{array}$ & $\begin{array}{l}\text { Propriedade de } \\
\text { Multidimensionalidade }\end{array}$ & $\begin{array}{l}\text { Propriedade de } \\
\text { Interobjetividade }\end{array}$ \\
\hline $\begin{array}{l}\text { Drowning in Plastic } \\
\begin{array}{l}\text { What Happens to the } \\
\text { Plastic We Throw Out }\end{array}\end{array}$ & Concentrada & Visível & Estática \\
Plastic Air & Diluída & Visível e Invisível & Interativa \\
\hline
\end{tabular}

\section{Conclusão}

Os projetos aqui analisados, cada qual à sua maneira, apontam para uma multiplicidade de caminhos diante dos quais designers de informação se encontram, na tentativa de representar uma situação por natureza incognoscível. O conceito de hiperobjeto e suas três propriedades utilizadas nessa análise podem fornecer um caminho para capacitar a visualização de dados para o desafio cognitivo de dar forma ao inimaginável, apontando para a necessidade de projetos futuros formularem representações diluídas em espaço e tempo (não-localidade), não restritas à camada perceptível a olho nu dos fenômenos (multidimensionalidade) e representativas de relações ecológicas complexas (interobjetividade). Nesse sentido, estudos mais amplos aplicando os critérios de análise a um maior número de visualizações - bem como sobre a recepção de visualizações ambientais junto a diferentes públicos - indicam caminhos para possíveis pesquisas futuras. Para o despertar da consciência ecológica, acreditamos que é necessário ir além de paradigmas baseados na neutralidade da informação visual, apostando na capacidade de provocar reações emocionais. Além disso, queremos estimular a reflexão e discussão acerca dos limites e potências da visualização de dados como ferramenta de resposta a um real que cada vez mais parece nos escapar à percepção, ao mesmo tempo em que se aproxima rápida e agressivamente.

\section{Referências}

Crutzen, P. J., \& Stoermer, E. F. (2000). "The 'Anthropocene"'. In The Future of Nature (p. 479490). Yale University Press.

Cairo, A. (2013). The functional art: an introduction to information graphics and visualization. Berkeley, CA: New Riders.

Copelin, L., Gardner, P., Morton, T. (2018). Hyperobjects for Artists. Marfa, TX: Ballroom Marfa. https://thecreativeindependent.com/library/hyperobjects-for-artists/ 
D'Ignazio, C., \& Klein, L. F. (2020). Data feminism. The MIT Press.

Guglielmino, M. (2021, Feb. 26). Feeling Scale Is Necessary to Inspire Action. Nightingale. https://medium.com/nightingale/feeling-scale-is-necessary-to-inspire-action-b894b1ba5d41

Jaskulsky, L., \& Besel, R. (2013). Words That (Don't) Matter: An Exploratory Study of Four Climate Change Names in Environmental Discourse. Applied Environmental Education \& Communication, 12(1), 38-45. https://doi.org/10.1080/1533015X.2013.795836

Knaflic, C. N. (2015). Storytelling with data: a data visualization guide for business professionals. Hoboken, New Jersey: John Wiley \& Sons, Inc.

Kirk, A. (2019). Data visualisation: a handbook for data driven design. Sage Publications Inc.

Krenak, A. (2019). Ideias para adiar o fim do mundo. São Paulo: Companhia das Letras.

Latour, B. (2014). Um Prometeu cauteloso?: alguns passos rumo a uma filosofia do design (com especial atenção a Peter Slotedijk). Agitprop: revista brasileira de design 6(58).

Lewis, S. L., \& Maslin, M. A. (2015). Defining the Anthropocene. Nature, 519(7542), 171-180. https://doi.org/10.1038/nature14258

Longhi, R. R., \& Cordeiro, W. R. (2018). No jornalismo imersivo, o infográfico é hiper. LíBERO, 21(42), 159-174.

Meyer, G. E. C. (2020). Vivendo no Antropoceno: O Design e a Arte lidando com os modos de uma Época Impossível. Estudos em Design, 28(2). https://doi.org/10.35522/eed.v28i2.987

Morin, E. (1990). Introdução ao pensamento complexo. $5^{\text {a }}$ Ed. Porto Alegre: Sulina, 2007.

Morton, T. (2010). The ecological thought. Harvard University Press.

Morton, T. (2013). Hyperobjects: Philosophy and ecology after the end of the world. University of Minnesota Press.

Morton, T. (2015, Jan. 19). Introducing the idea of 'hyperobjects'. High Country News, 47(1).

https://www.hcn.org/issues/47.1/introducing-the-idea-of-hyperobjects

Papanek, V. (1971). Design for the Real World: Human Ecology and Social Change. New York: Pantheon Book, 1971.

Rittel, H. W. J., \& Webber, M. M. (1973). Dilemmas in a general theory of planning. Policy Sciences, 4(2), 155-169. https://doi.org/10.1007/BF01405730

Steele, J. \& Iliinsky, N. (2011). Designing Data Visualizations. Sebastopol, CA: O'Reilly Media.

Steffen, W., Broadgate, W., Deutsch, L., Gaffney, O., \& Ludwig, C. (2015). The trajectory of the Anthropocene: The Great Acceleration. The Anthropocene Review, 2(1), 81-98. https://doi.org/10.1177/2053019614564785

Tufte, E. (1983). The visual display of quantitative information. Graphics Press.

Tsing, A., Swanson, H. A., Gan, E., \& Bubandt, N. O. (Eds.) (2017). Arts of Living on a Damaged Planet: Ghosts and Monsters of the Anthropocene. University of Minnesota Press.

\section{Sobre os autores}

Rodolfo Augusto de Araujo Almeida, Mestrando, UFRJ, Brasil <rodolfoalmd@gmail.com>

Doris Kosminsky, Doutora, UFRJ, Brasil <doriskos@gmail.com> 